\title{
Self-Associating Peptides for Modular Bifunctional Conjugation of Tetramer Macromolecules in Living Cells
}

Marc Vigneron ${ }^{\dagger}$, Frank Dietsch $^{\dagger}$, Laurent Bianchetti ${ }^{\ddagger}$, Annick Dejaegere ${ }^{\ddagger}$, Yves Nominé ${ }^{\ddagger}$, Agnès Cordonnier $^{\dagger}$, Guy Zuber ${ }^{\dagger}$, Bruno Chatton ${ }^{\dagger}$, and Mariel Donzeau ${ }^{\dagger *}$

†Université de Strasbourg, UMR7242 Biotechnologie et Signalisation Cellulaire, Ecole Supérieure de Biotechnologie Strasbourg, F-67412 Illkirch, France.

${ }^{\ddagger}$ Department of Integrated Structural Biology, Institut de Génétique et de Biologie Moléculaire et Cellulaire (IGBMC), INSERM U1258/CNRS UMR 7104/Université de Strasbourg, 1 rue Laurent Fries, BP 10142, 67404, Illkirch, France.

*mariel.donzeau@unistra.fr

\section{Abstract:}

Monitoring the assembly of macromolecules to design entities with novel properties can be achieved either chemically creating covalent bonds or by non-covalent connections using appropriate structural motifs. In this report, two self-associating peptides (named K3 and E3) that originate from p53 tetramerization domain were developed as tools for highly specific and non-covalent heterotetramerization of two bio-molecules. The pairing/coupling preferences of $\mathrm{K} 3$ and $\mathrm{E} 3$ were first evaluated by molecular modeling data and confirmed using circular dichroism spectroscopy, size-exclusion chromatography and biological assays. Regardless of the moieties fused to $\mathrm{K} 3$ and $\mathrm{E} 3$, these two peptides self-assembled into dimers of dimers to form bivalent heterotetrameric complexes that proved to be extremely stable inside of living cells. The benefits of the multivalency in terms of avidity, specificity and expanded functional activity were strikingly revealed when the Proliferating Cell Nuclear Antigen (PCNA), which is essential for DNA replication, was targeted using a heterotetramer presenting both an antibody fragment against PCNA and a specific PCNA binder peptide. In vitro heterotetramerization of these two known PCNA ligands increased their binding efficiencies to PCNA up to 80-fold compared to the best homotetramer counterpart. In cellulo, the heterotetramers were able to efficiently inhibit DNA replication and to trigger cell death. Altogether, we demonstrate that these two bi-selective self-assembling peptidic domains offer a versatile non-covalent conjugation method that can be easily implemented for protein engineering.

Keywords: bifunctional, heterotetramer, peptide, PCNA, modularity, non-covalent. 


\section{INTRODUCTION}

Strengthening associations between molecules and their specific targets can be successfully achieved using multivalency. This simple approach, in which multiple ligands on one entity interact simultaneously to multiple receptors on another one, enhances the total binding residence time between partners, translating in improved functional affinity. ${ }^{1}$ This property, also called avidity, has been explored to enhance the binding affinity of antibody fragments to their targets using natural oligomerization domains such as amphipathic helices or leucine-zipper domains. ${ }^{2,3}$ Beside multivalency, novel functionalities can be reached by connecting together two or more distinct effector molecules. ${ }^{4-6}$ For example, a bi-functional chimera targeting two distinct sites of HPV E6 oncoprotein has been successful in inducing the death of HPV-positive cells ${ }^{4}$ and a tri-specific antibody that could confer protection against several HIV strains has been engineered. ${ }^{7}$ The key to access this diversity is the link between molecules. This can be achieved using covalent bonds ${ }^{4,8}$ or alternatively using noncovalent association modes ${ }^{6}$.

In this work, we describe the use of 51 amino-acid long self-associating peptides for non-covalent assembly of two distinct macromolecules to create modular bi-functional tetravalent entities. These self-assembling peptides originated from the tetramerization domain of the human p53. The p53 tetramerization domain consists of a $\beta$-strand followed by an $\alpha$-helix. ${ }^{9}$ The structure of the tetramer is a symmetric dimer of primary dimers, which is mediated solely by helix-helix contacts. The tetramer is stabilized not only by hydrophobic interactions but also by a number of salt bridges, involving residues E343, E346 and $\mathrm{K} 351 .{ }^{10,11}$ We exploited the variants $\mathrm{K} 351 \mathrm{E}$ and $\mathrm{E} 343 \mathrm{~K} / \mathrm{E} 346 \mathrm{~K}^{11}$, henceforth referred to as $\mathrm{E} 3$ and $\mathrm{K} 3$, respectively (Figure $1 \mathrm{~A}$ ), and tested their efficiency in promoting the formation of highly stable bi-functional based molecules, either in vitro and in cellulo. 
A

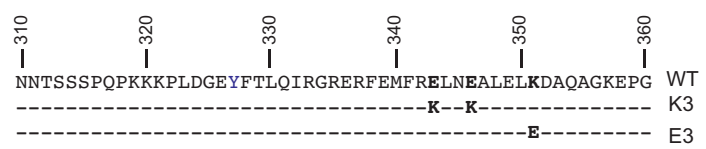

B

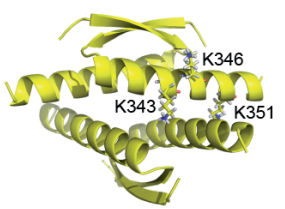

(K3) 4

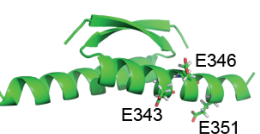

(E3)2
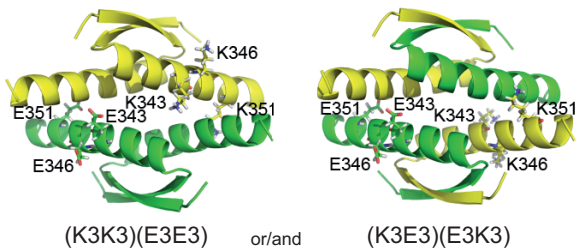

(K3E3)(E3K3) or/and

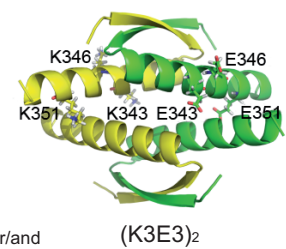

C

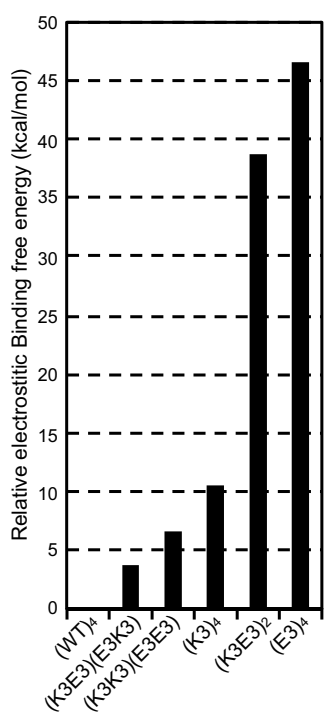

D

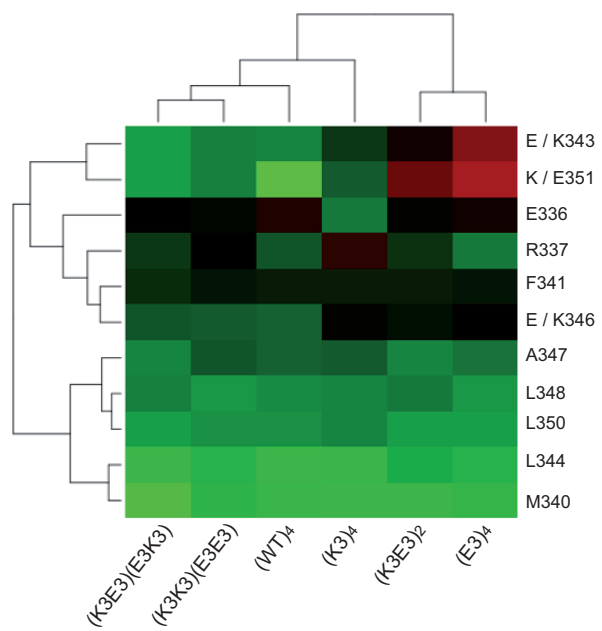

Figure 1. Structures and models of the dimeric and tetrameric architectures. (A) Sequences of the wild type p53 tetramerization domains and of E3 and K3 variants. (B) The molecular models of K3 homotetramer and E3 dimer as well as the possible heterotetramers are shown. The K3 and E3 domains are colored in yellow and green, respectively. Atoms of $\mathrm{K}$ or $\mathrm{E}$ residues at positions 343,346 and 351 are represented with colored sticks (red $=$ oxygen, blue $=$ nitrogen, white $=$ hydrogen). (C) Relative electrostatic contributions to the binding free energies at the $\alpha$-helix interface in tetramers. The MM-PBSA electrostatic contribution to the binding free energy of the WT peptide is used as a reference point. Positive values indicate destabilization with respect to the WT. (D) Heatmap representation of per-residue binding free energies at the $\alpha$-helix interface in tetramers. The dendrograms on the left and top show clusters of residues and group of tetramers, respectively. Residues are colored from bright green $(-4 \mathrm{kcal} / \mathrm{mol})$ to bright red $(+4 \mathrm{kcal} / \mathrm{mol})$ according to their contribution to the binding free energy, with black corresponding to no contribution. The hierarchical clustering was based on the free energies, and show either structures that have similar energetic contributions (displayed on top), or group of amino acids that have similar contributions across all structures (displayed on the left). 


\section{RESULTS}

\section{In silico evaluation of heterotetramer stabilities}

First, the stability of the E3 and K3 peptides to assemble into a tetrameric complex was evaluated in silico using molecular modeling. The previously solved structure of the wildtype p53 tetramer (PDB code $1 \mathrm{C} 26)^{9}$ was selected as the starting structure to construct dimers and tetramer models of the peptide variants (Figure 1B and S1A). The total and perresidue energetic contributions to inter-molecular interactions were calculated and decomposed into electrostatic, van der Waals and solvent accessible surface components. The total binding free energy of each system was estimated from potential energy minimized structures using the Molecular mechanics Poisson-Boltzmann surface area method (the lower total binding free energy value, the higher stability) ${ }^{12,13}$ (see Materials and Methods). The calculations show that the $N$-terminal $\beta$-sheet of the peptide brings into contact monomers to form primary dimers (Figure S1B and S1C). Binding free energies are not significantly different between WT and mutant $\beta$-sheet dimers, which show that E343, E346 and K351 mutations do not compromise stability (Figure S1C). The $\alpha$-helical charged interface has, however, an essential role in modulating the tetramer affinity (Figure $1 \mathrm{C}$ and S1B). Analysis of the individual contributions of amino acids to the stabilization of the helical interface of the tetramers shows a cluster of hydrophobic residues (M340, L344, A347, L348 and L350) that stabilize all architectures, while the contributions of charge amino acids varies significantly between the complexes (Figure 1D). The energetic data reveal that the mutations favor the formation of heterotetramers over homotetramers $(\mathrm{K} 3)_{4}$ or $(\mathrm{E} 3)_{4}$ (Figure $1 C$ and 1D). Interestingly, all architectures that involve pairing of E3 with itself through the helical interfaces are strongly destabilized, while the electrostatic repulsion of equivalent architectures of the $\mathrm{K} 3$ mutants is less important (Figure $1 \mathrm{C}$ ). As a result, the formation of $(\mathrm{E} 3)_{4}$ and $(\mathrm{K} 3 \mathrm{E} 3)_{2}$ tetramers appears unlikely, $(\mathrm{K} 3)_{4}$ tetramer could be observed, while two architectures are possible for heterotetramers, (K3K3)(E3E3) and (K3E3)(E3K3).

\section{In vitro formation of heterotetramer biomolecules}

To evaluate modularity and efficiency of heteromerization, the E3 and K3 peptides were conjugated to bioactive macromolecules of various molecular masses and activities, such as ligands targeting the Proliferating Cell Nuclear Antigen (PCNA). PCNA is an ubiquitous eukaryotic protein essential for DNA replication and DNA repair ${ }^{14}$ and its inhibition is considered to be a promising anticancer strategy. ${ }^{15}$ PCNA assembles into a ring-shape homo-trimer that encircles the DNA and facilitates DNA processing by recruiting various factors mainly via association at its Inter Domain Connector Loop (IDCL). A high affinity con1 (for consensus motif 1 ) peptide rationally designed for binding to the IDCL ${ }^{16}$ and an antiPCNA single-chain variable fragment (scFv, clone P40M1) ${ }^{17}$ were selected. The E3 and K3 
peptides were fused, respectively to the C-terminus of the scFv anti-PCNA (thereinafter referred to as anti-PCNA) and the con1 peptide by genetic engineering. The recombinant proteins were expressed in $E$. coli and purified by immobilized metal affinity chromatography (IMAC). The oligomeric states of the purified biomolecules were then analyzed using size exclusion chromatography (SEC) (Figure 2A). The 37-kDa anti-PCNA-E3 protein displayed a single peak with an apparent molecular weight of $75-\mathrm{kDa}$ corresponding to a dimer. In the case of the $12-\mathrm{kDa}$ con1-K3 protein, a single peak corresponding to a tetramer with an apparent molecular weight of about 45-kDa was observed. When equimolar amounts of antiPCNA-E3 and con1-K3 proteins were incubated together 5 min and then analyzed by SEC, an apparent $100-\mathrm{kDa}$ assembly was produced, which was assigned to a (con1-K3) 2 (anti$\mathrm{PCNA}-\mathrm{E} 3)_{2}$ complex. The elution profile was devoid of peaks corresponding to (con $\left.1-\mathrm{K} 3\right)_{4}$ or (anti-PCNA-E3) $)_{2}$ confirming that the (con1-K3) $)_{4}$ homotetramer dissociates and leads to the more stable (con1-K3 $)_{2}(\text { anti-PCNA-E3 })_{2}$ complex. Altogether, these results are in agreement with the molecular modeling data.

The secondary structure content of the K3 and E3 was next explored using far-UV Circular Dichroism (CD) spectroscopy and the content of secondary structure elements was estimated using CDPro suite software. ${ }^{18}$ The con1-tagged $\mathrm{K} 3$ and $\mathrm{E} 3$ constructs were used since the relative small molecular weight of the con1 peptide (6-kDa) should minimize its contribution to the CD signal compared with the large ScFv anti-PCNA protein (29-kDa). The far-UV CD spectra of the tagged con1 constructs are highly similar (Figure 2B). The con1-E3 folded in $37 \pm 2 \%$ of $\alpha$-helix, $9 \pm 1 \%$ of $\beta$-sheets and $54 \pm 3 \%$ of unassigned secondary structures (Table S1). The proportions of secondary structures stayed almost constant regardless of the point mutations. A thermal denaturation analysis of (con1-E3) $)_{2}$, (con1-K3) and (con1-E3) $)_{2}(\operatorname{con} 1-K 3)_{2}$ was performed by measuring the change of the $C D$ signal at 222 $\mathrm{nm}$ as the temperature increases (Figure $2 \mathrm{C}$ ). While the melting temperatures and profiles of the (con 1-E3) $)_{2}$ and (con $\left.1-\mathrm{K} 3\right)_{4}$ were highly similar $\left(64.6^{\circ} \mathrm{C} \pm 0.7^{\circ} \mathrm{C}\right.$ and $67.3^{\circ} \mathrm{C} \pm 0.2^{\circ} \mathrm{C}$, respectively), the (con1-E3) $)_{2}(\mathrm{con} 1-\mathrm{K} 3)_{2}$ heterodimers exhibit a significant increase in thermal stability $\left(76^{\circ} \mathrm{C} \pm 1.0^{\circ} \mathrm{C}\right)$, as expected ${ }^{11}$. A biphasic-melting curve was observed for the heterotetramer construct, which may be induced by an overall stabilization of the complex, leading to the first phase in the melting curve, the second phase being due to the denaturation of the two homodimers. These findings are in line with the conclusions drawn with the free binding energy calculations. Remarkably, the thermal renaturation compares very well with the thermal denaturation (Figure $2 \mathrm{C}$ ), suggesting either that the final state above $76^{\circ} \mathrm{C}$ does not correspond to the unfolded state, or that the unfolding process is reversible, or that the charged nature of the protein domains prevent irreversible aggregation. 
A

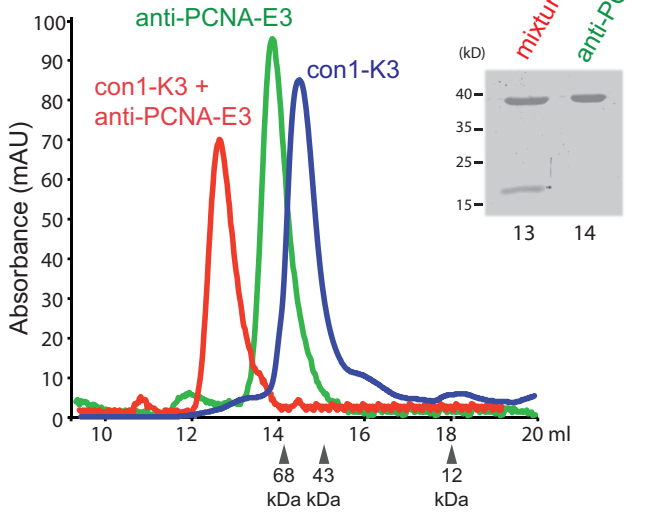

C

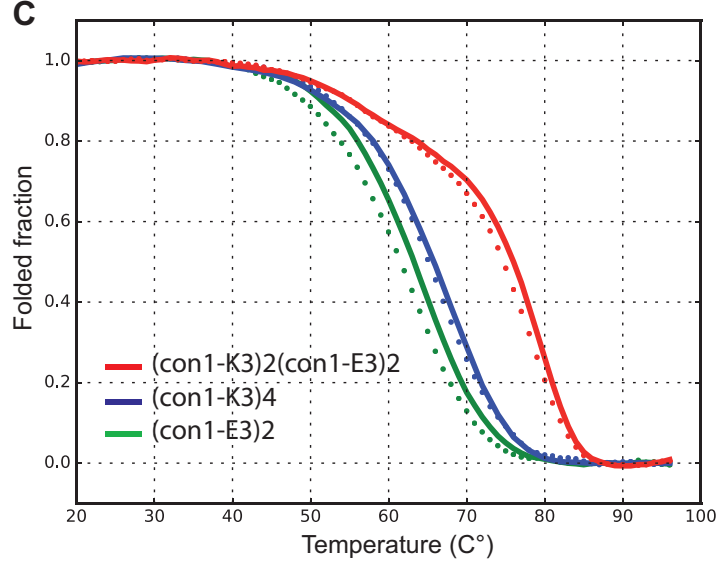

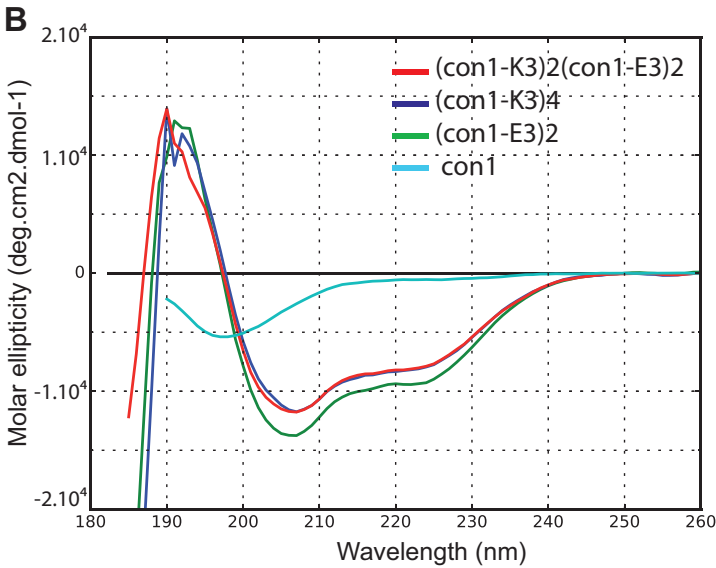

D

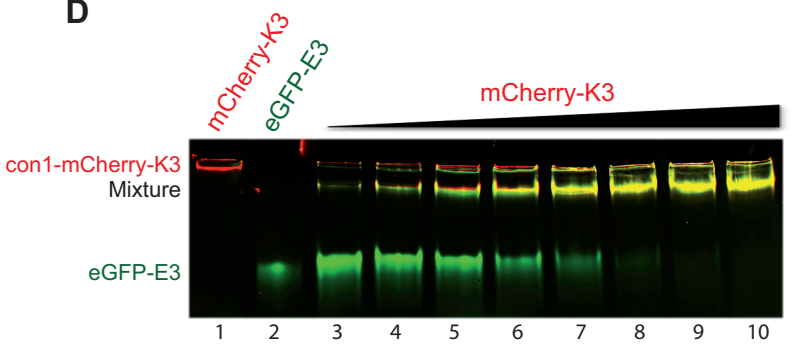

Figure 2. Physicochemical analysis of the heterotetramerization abilities of $K 3$ and E3 constructs. (A) Analytical gel filtration of purified anti-PCNA-E3 (green), con1-K3 proteins (blue) and equimolar anti-PCNAE3/con1-K3 mixture (red). The column was pre-calibrated with standard proteins as indicated (BSA, Ovalbumin and Cytochrome C). $2 \mu \mathrm{g}$ of each peak fraction (as indicated by numbering) was analyzed by SDS-PAGE and by Coomasie blue staining. (B) Far-UV Circular Dichroism spectra of the indicated assemblies were recorded for samples at a monomeric concentration of $50 \mu \mathrm{M}$ in phosphate saline Buffer. CD signal is expressed in mean residue ellipticity $\left(\right.$ deg. $\left.\mathrm{cm}^{2} \cdot \mathrm{dmol}^{-1}\right)$. Data were collected in the $185-270 \mathrm{~nm}$ range at $20^{\circ} \mathrm{C}$. Experiments have been done in triplicate. (C) Thermal denaturation (solid lines) and renaturation (dotted lines) data of indicated samples at monomeric concentration of $100 \mu \mathrm{M}$ were recorded at $222 \mathrm{~nm}$ as temperature increased from 20 to $96^{\circ} \mathrm{C}$ or decreased from 96 to $20^{\circ} \mathrm{C}$, respectively. The fraction of folded form was extracted from the variation of the $C D$ signal over temperature. (D) Native polyacrylamide gel analysis of the (eGFP-E3) $)_{2}$ (con1-mCherry-K3) ${ }_{2}$ heterotetramer formation by titration of eGFP-E3 protein with increasing amounts of con1-mCherry-K3 protein in cell lysate, as indicated. The presence of the fluorescent moieties was revealed using Typhoon device.

We further assessed the oligomeric behavior of the K3 and E3 domains in presence of cell constituents as they might compete and interfere with the oligomerization ability of the peptides. For that purpose, the E3 and K3 tags were fused to the enhanced-Green Fluorescent Protein (eGFP) and to the con1-mCherry by genetic engineering. The fusion proteins were then expressed in HeLa cells by transfection of DNA plasmids. 24 hours after transfection, increased amounts of con1-mCherry-K3-expressed cell lysate were mixed to steady amounts of eGFP-E3-expressed cell lysate. After 5 minutes incubation at room 
temperature, the mixtures were analyzed on native polyacrylamide gel electrophoresis. As shown in Figure 2D, the eGFP-E3 was gradually titrated by increasing amounts of con1$\mathrm{mCherry-K3}$ leading to the formation of a yellow fluorescent band. This band was assigned to the (con1-mCherry-K3) $)_{2}$ (eGFP-E3) $)_{2}$ tetramer and its detection clearly demonstrates the specific and the stable association of the E3 and K3 peptides even in presence of cellular constituents. These data confirm that the K3 alone remains a homotetramer, which dissociates to form a dimer of dimer in the presence of E3.

\section{In cellulo conjugation of macromolecules via E3 and K3 peptides}

The ability of the K3 and E3 association to enable conjugation of macromolecules inside of living cells was then investigated by tagging various fluorescent proteins and high affinity antibodies. In the first experiment, we tested whether the eGFP protein could be used as a detection marker to reveal chromatin-bound PCNA. Plasmids encoding the con1mCherry-E3 and eGFP-NLS-K3 were transiently expressed into MRC5 cells. The SV40 nuclear localization signal (NLS) was fused to the eGFP-K3 to enable nuclear transport of the tetramer complex. The (con1-mCherry-E3) ${ }_{2}$ diffused homogeneously inside the

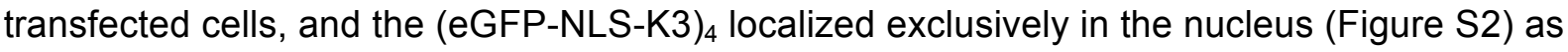
expected. Cytoskeletal buffer (CSK) treatment prior cell fixation was then used to remove freely and loosely held proteins, and to reveal proteins tightly bound to the chromatin. As shown in figure $3 \mathrm{~A}$, only the (con1-mCherry-E3) ${ }_{2}$ detected PCNA at nuclear foci, whilst the (eGFP-NLS-K3 $)_{4}$ was washed out. When co-expressed in the same cell, the eGFP-NLS-K3 associated strongly enough with the con1-mCherry-E3 to detect chromatin-bound PCNA visualized by the yellow speckled in the nucleus (Figure $3 \mathrm{~A}$ ).

We next evaluated whether the interaction between E3 and K3 could assist the recruitment of the DNA polymerase $\eta$ in the proximity to PCNA (Figure 3B). The DNA Polymerase $\eta$ is implicated in translesion DNA synthesis (TLS) and co-localizes with PCNA at replication foci after DNA damage. ${ }^{19}$ MRC5 cells were simultaneously co-transduced with plasmids expressing con1-mCherry-E3 and the DNA polymerase $\eta$ fused to enhanced yellow fluorescent protein (EYFP), together with a purified $\mathrm{V}_{\mathrm{H}} \mathrm{H}$ anti-eGFP fused to $\mathrm{K} 3$ peptide. This $\mathrm{V}_{\mathrm{H}} \mathrm{H}$ binds with high affinity to both eGFP and EYFP. ${ }^{20}$ At 24 hours following transduction, cells were treated with CSK buffer to wash away unbound proteins. As shown in figure 3B, con1-mCherry-E3 alone localized at nuclear foci. When co-transduced together with the $\mathrm{V}_{\mathrm{H}} \mathrm{H}$ anti-eGFP-K3, the con1-mCherry-E3 was able to recruit EYFP-polymerase $\eta$ via the $\mathrm{V}_{\mathrm{H}} \mathrm{H}$ at the replication foci visualized by the strong yellow speckled (Figure 3B). The co-localized signal was dependent of the specific interaction between E3 and K3 peptides as no signal was detectable in the presence of an unrelated $\mathrm{V}_{\mathrm{H}} \mathrm{H}$ without $\mathrm{K} 3$ or in the absence of con1- 
A
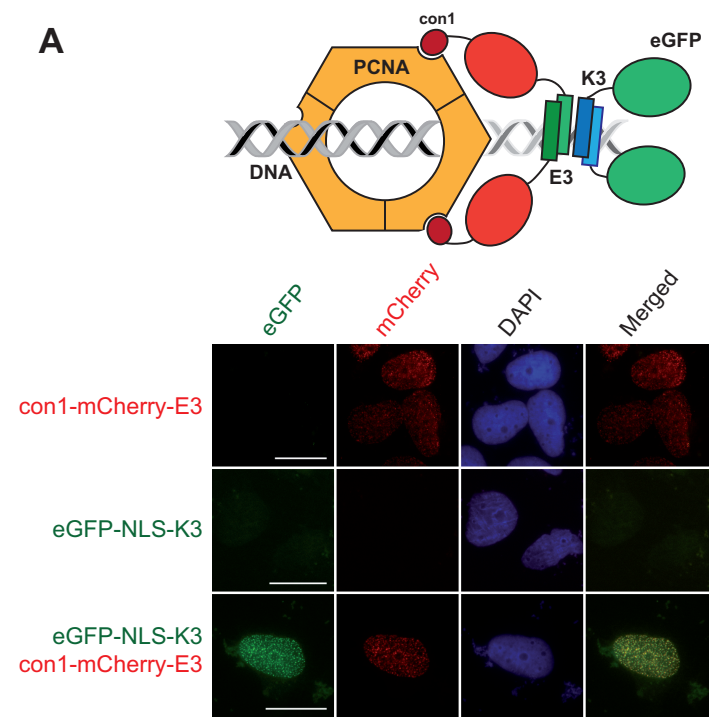

C

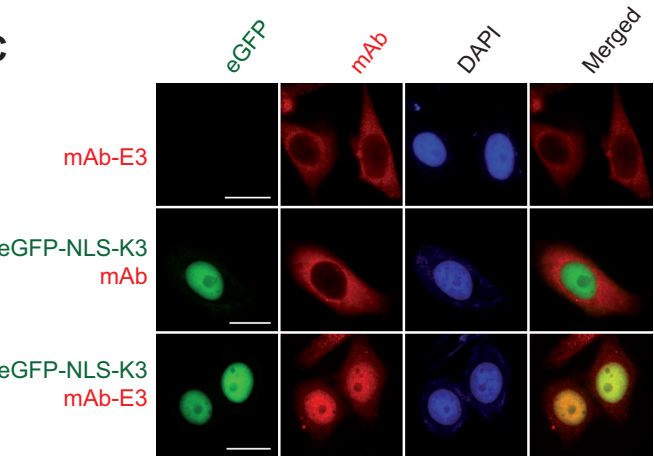

B
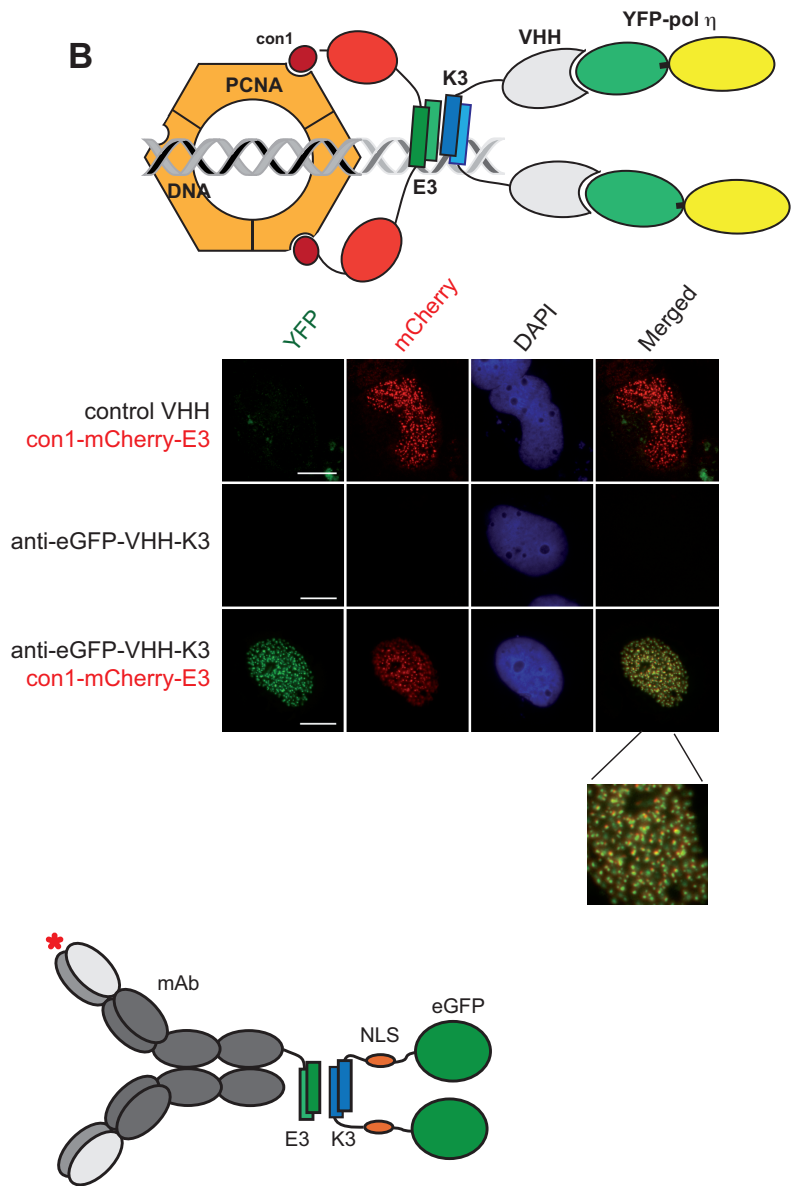

Figure 3. Modular tetramerization of macromolecules in living cells for detection and siteselected re-localization strategy. (A) Direct fluorescent detection of chromatin-bound PCNA in living MRC5 cells after DNA transfection of eGFP-NLS-K3 and con1-mCherry-E3 expression plasmids either alone or in combination. Nuclei were stained with DAPI (blue). Scale bar $20 \mu \mathrm{m}$. (B) MRC5 cells were transfected with the YFP-DNA polymerase $\eta$ expression plasmid with or without con1-mCherry-E3 and either transduced with a control VHH or an anti-eGFP-VHH as indicated. 24h post-transfection cells were fixed and mounted. YFP-DNA polymerase $\eta$ and con1-mCherry-E3 were detected by direct fluorescence. Nuclei were stained with DAPI (blue). Scale bar $10 \mu \mathrm{m}$. (C) HeLa cells transfected with eGFP-NLS-K3 expression plasmid were electro-transduced with protein-G purified mAb covalently bound or not to E3 peptide. 24h post-transfection, cells were fixed and mounted. The transduced mAb was detected with an anti-mouse Alexa566. Nuclei were stained with DAPI (blue). Scale bar $20 \mu \mathrm{m}$. Images were taken by fluorescence microscopy. Cartoons represent the heterotetramer complexes.

Finally, a monoclonal antibody ( $m A b)$ directed against the activating transcription factor 7 $\left(\right.$ ATF7) ${ }^{21}$ was chemically coupled to a thiol-containing synthetic E3 peptide. This antibody was chosen because it recognizes endogenous ATF7 $(1 \mathrm{~A} 7)^{22}$ bound to the chromatin. ${ }^{23}$ The mAb-E3 conjugate was then delivered by electroporation inside HeLa cells together with an eGFP-NLS-K3 expression vector (Figure 3C). The conjugated mAb-E3 alone exclusively localized into the cytoplasm of HeLa cells like its unconjugated form. However, when 
expressed together with the eGFP-NLS-K3 construct, the mAb-E3 was entirely redirected to the nucleus, while the unconjugated mAb was not.

These in cellulo experiments demonstrate that E3 and K3 peptides are very efficient and specific tools for the conjugation of bio-macromolecules in living cells and for the relocalization of selected proteines at chosen intracellular sites.

\section{Biological activities of the bio-conjugates in living cells}

Biological activities of heterotetramer molecules were next assessed using PCNA as a target. Multivalency is known to increase the apparent binding efficiency by mean of avidity, thus both heterotetramers (con1-E3) $)_{2}(\text { anti-PCNA-K3 })_{2}$ and (con1-K3) $)_{2}$ (anti-PCNAE3) $)_{2}$ biomolecules were first tested using an indirect ELISA (Figure 4A). Multimeric PCNA ligands were able to detect plastic-immobilized recombinant PCNA, yet with different binding

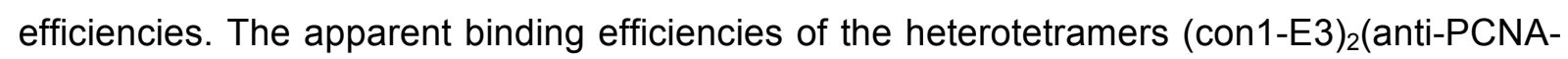
$\mathrm{K} 3)_{2}$ and (con1-K3) ${ }_{2}$ (anti-PCNA-E3) $)_{2}$ were enhanced by approximately 80 -fold and 1000 -fold compared to the homotetramers (anti-PCNA-K3) ${ }_{4}$ and (con1-K3) $)_{4}$, respectively. Indeed, the relative binding efficiency was $0.0040 \mu \mathrm{M}( \pm 0.0008)$ for both heterotetramers, $0.29 \mu \mathrm{M}( \pm$ $0.09)$ for the anti-PCNA-K3 homotetramer and $4.5 \mu \mathrm{M}( \pm 2.0)$ for the con1-K3 homotetramer. These results point to a cooperative effect between the two different ligands for improved binding to PCNA. The con1 (for consensus motif 1 ) is a peptide rationally designed for binding to the IDCL of PCNA. ${ }^{16}$ Thus, to confirm the cooperative effect, we compared the binding abilities of the (con1-K3) $)_{4}$, the (anti-PCNA-E3) $)_{2}$ and the (con1-K3) $)_{2}$ (anti-PCNA-E3) $)_{2}$ to PCNA mutated in its IDCL region. Three PCNA mutants were tested for their binding to a well-characterized PIP-box domain of $12^{24}$ (Figure S3A). Among these PCNA mutants, only one, the E124A, could no longer interact with the PIP-box domain of p12 protein. Thus, the PCNA-E124A protein was used for an indirect ELISA. A clear lost of cooperative effect was observed because the (con1-K3) $)_{2}(\text { anti-PCNA-E3 })_{2}$ had a binding efficiency similar to that of the (anti-PCNA-E3) 2 , which was due to the absence of con1 binding to PCNA-E124A (Figure S3B). The binding efficiency of the heterotetramer molecules was next evaluated by immunofluorescence detection of PCNA after membrane permeabilization and cell fixation. The endogenous nuclear PCNA was barely detected with the anti-PCNA and with the (anti$\mathrm{PCNA}-\mathrm{E} 3)_{2}$ (Figure 4B). A signal diffusely distributed in the nucleus and in the cytoplasm became visible using the (anti-PCNA-K3) ${ }_{4}$ and the (con1-K3) 4 . However, only the (con1$\mathrm{K} 3)_{2}$ (anti-PCNA-E3) $)_{2}$ heterotetramer was able to clearly localize PCNA at nuclear foci, confirming the cooperative effect measured by indirect ELISA. 
A

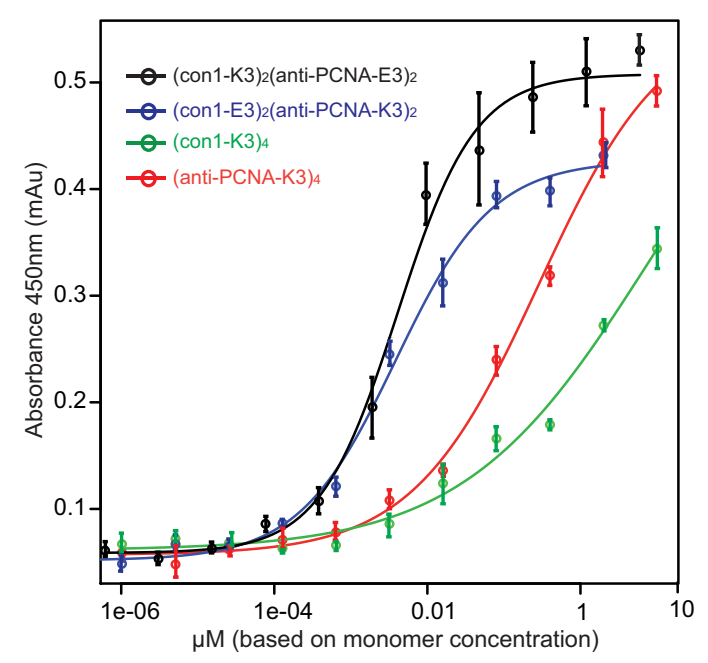

B
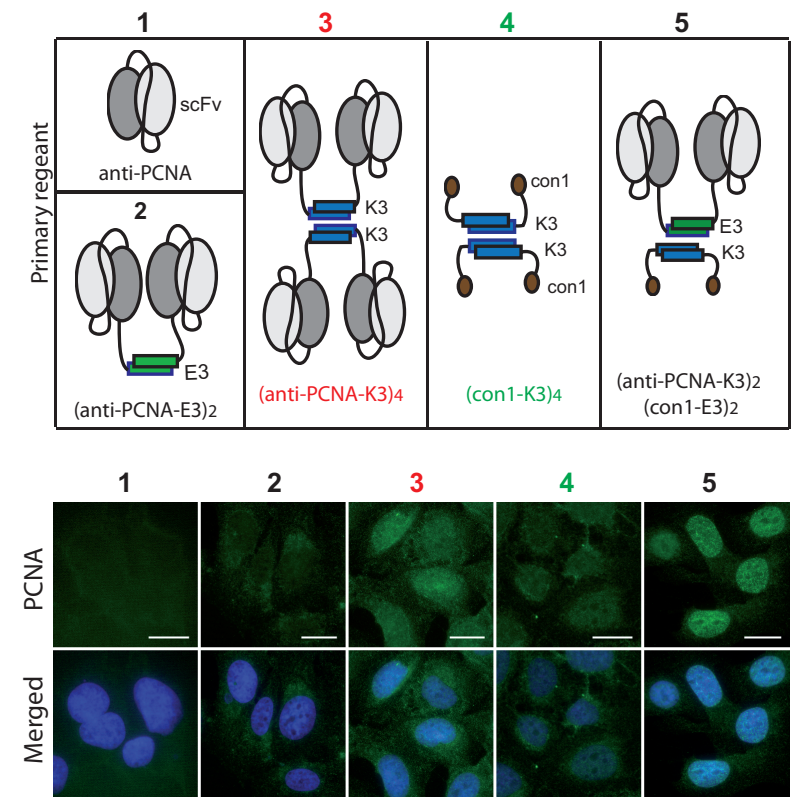

Figure 4. Properties of the bi-functional PCNA ligands. (A) Apparent binding properties of tetramer complexes were measured by indirect ELISA again immobilized purified PCNA at a concentration of $20 \mu \mathrm{g} / \mathrm{ml}$. Binding curve average of three independent experiments are shown. Relative binding efficiency is $0.0040 \mu \mathrm{M}( \pm 0.0008)$ for the heterotetramers, $0.29 \mu \mathrm{M}( \pm 0.09)$ for the anti-PCNA-K3 homotetramer and $4.5 \mu \mathrm{M}( \pm 2.0)$ for the con1-K3 homotetramer. (B) Detection of PCNA in fixed HeLa cells by conventional immunofluorescence. The binding of purified tagged proteins to PCNA ( $5 \mathrm{nM}$ based on monomer concentration) was detected using the anti-myc 9E10 monoclonal antibody (mAb) followed by goat anti-mouse Ab-conjugated with Alexa Fluor 488 (green). Nuclei were stained with DAPI (blue). Scale bar $20 \mu \mathrm{m}$.

Hindering PCNA activity with peptides binding to its IDCL region leads to partial DNA replication inhibition. ${ }^{25}$ To explore if the recombinant biomolecules could inhibit DNA elongation, the purified (eGFP-K3) $)_{4}$, (con1-K3) $)_{4},(\text { anti-PCNA-E3) })_{2}$ and (con1-K3) ${ }_{2}$ (anti-PCNAE3) ${ }_{2}$ proteins were transduced in MRC5 cells by electroporation. ${ }^{17}$ The recombinant proteins were electro-transferred in nearly $100 \%$ of cells (Figure S4A), as expected. Forty-eight hours after transduction, pulse-chase experiments were performed for an additional 16 hours using a modified thymidine analogue (EdU) that is incorporated in newly synthesized DNA and that can be fluorescently labeled. Around $60 \%$ of the cells transduced with the (eGFP-K3) $)_{4}$ or with the (anti-PCNA-E3) ${ }_{2}$ moieties presented a bright stained of the nuclei indicating DNA elongation, whilst almost no staining was observed for cells transduced with the (con1-K3 $)_{4}$ or with the (con1-K3 $)_{2}$ (anti-PCNA-E3) $)_{2}$ proteins, comparable to the cells blocked with high concentration thymidine halting DNA replication (Figure 5A). This inhibition of DNA replication was associated with cell death and the (con1-K3 $)_{2}(\text { anti-PCNA-E3 })_{2}$ heterotetramer appeared significantly more potent than the (con1-K3) $)_{4}$, yielding to more than $80 \%$ of cell death (Figure 5B and S4B). 

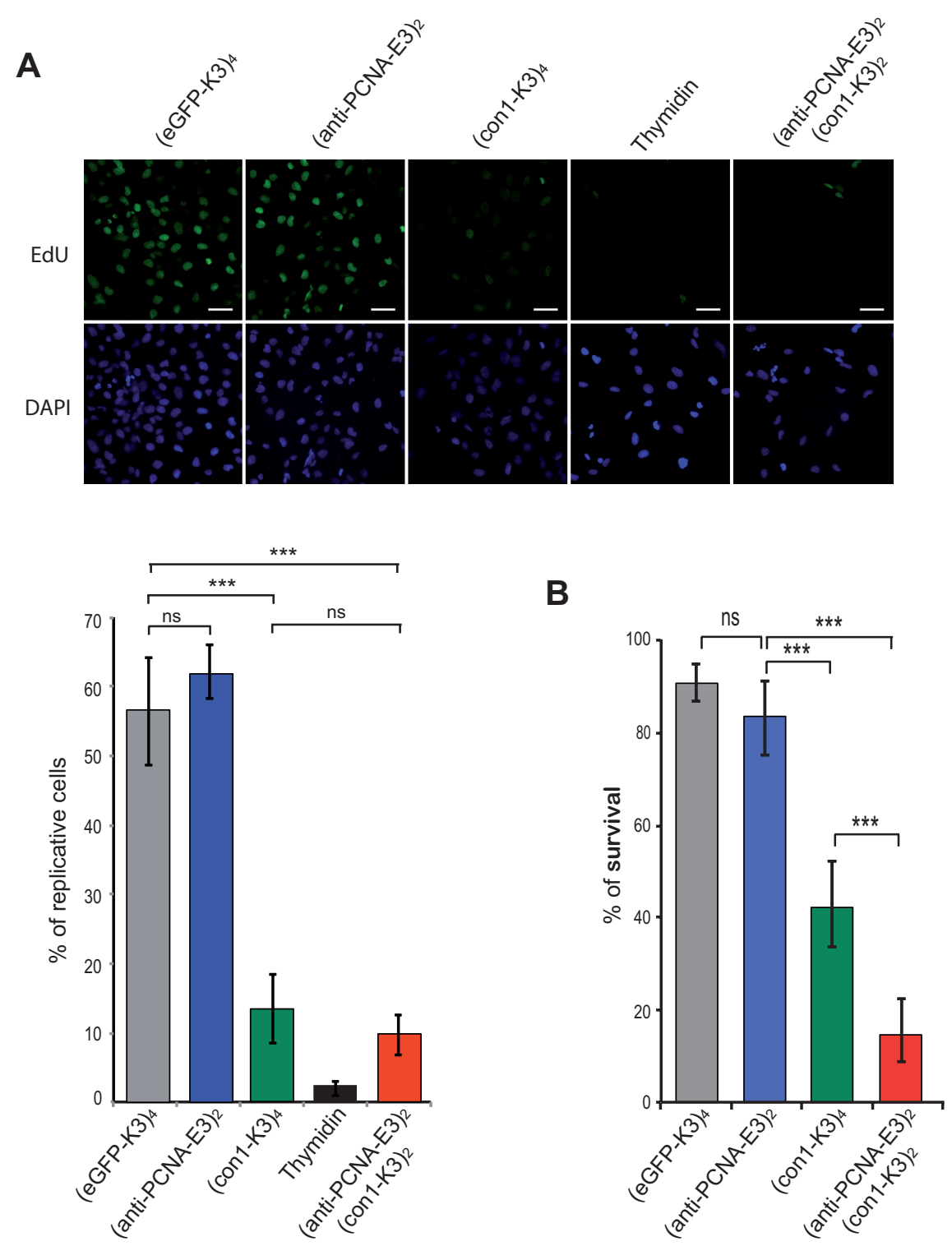

Figure 5. Bivalent tetramer (anti-PCNA-E3) ${ }_{2}(\operatorname{con} 1-\mathrm{K} 3)_{2}$ inhibits DNA replication and triggers cell death. (A) MRC5 cells were transduced with purified recombinant proteins as indicated. $48 \mathrm{~h}$ after transduction, cells were pulsed with $\mathrm{EdU}(0.5 \mu \mathrm{M})$ for an additional period of $16 \mathrm{~h}$, and fluorescently labelled after cell fixation. Bright green staining of the nuclei indicates that the EdU is efficiently incorporated into the newly replicated DNA. Nuclei were stained with DAPI (blue). Scale bar $50 \mu \mathrm{m}$. Images were taken and analysed using ImageJ for quantification. The percentage of replicative cells corresponds to the average of three independent experiments. Error bars represent standard deviations. Student's t-test was performed: ${ }^{*} P<0.05,{ }^{* *}<0.01,{ }^{* * *} P<0.001$. (B) Percentage of cell survival was measured by counting the cells remaining attached to the plastic dishes, and was calculated by taking the number of cells treated with PBS as a reference. Analysis corresponds to the average of three independent experiments Error bars represent standard deviations. Student's t-test was performed: ${ }^{*} P<0.05,{ }^{* *}<0.01,{ }^{* * *} \mathrm{P}<0.001$.

Inhibition of DNA replication leading to replication fork stalling can induce doublestrands breaks (DSBs) and thus replicative stress. ${ }^{26}$ We monitored the phosphorylation of the histone variant $\mathrm{H} 2 \mathrm{AX}(\gamma \mathrm{H} 2 \mathrm{AX})$, a well defined biomarker of replicative stress ${ }^{27}$. The cells were treated as described previously, and after 64 hours, the presence of $\gamma \mathrm{H} 2 \mathrm{AX}$ was 
measured by immunofluorescence (Figure 6 ). More than $85 \%$ of the cells transduced with the (con1-K3) ${ }_{2}$ (anti-PCNA-E3) ${ }_{2}$ showed an extensive $\gamma \mathrm{H} 2 \mathrm{AX}$ staining, whilst only $25 \%$ for the cells transduced with (con1-K3) 4 . No $\gamma \mathrm{H} 2 \mathrm{AX}$ staining was observed in control cells and in cells transduced either with the (eGFP-K3) $)_{4}$ or with the (anti-PCNA-E3) $)_{2}$. These results confirm that association of anti-PCNA protein and con1 peptide via E3 and K3 domains in living cells generates bivalent heterotetramer biomolecules, which provide an important benefit in term of blocking DNA replication enough to trigger large number of DSBs and hence cell death.
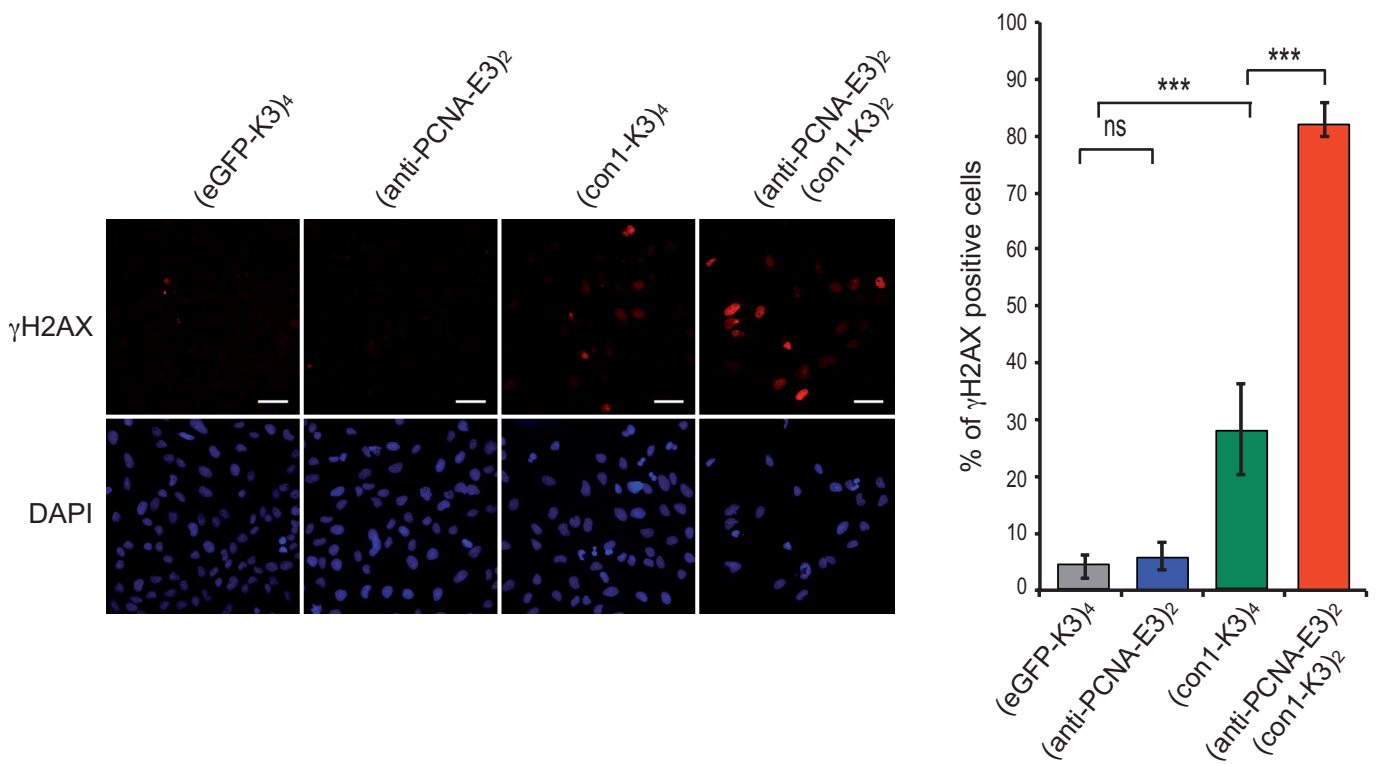

Figure 6. Heterotetramer (anti-PCNA-E3) $)_{2}(\operatorname{con} 1-\mathrm{K} 3)_{2}$ biomolecules trigger replicative stress. (A) MRC5 cells transduced with purified recombinant proteins as indicated were fixed after $64 \mathrm{~h}$. Phosphorylation of $\gamma-\mathrm{H} 2 \mathrm{AX}$ was detected using a mAb anti- $\gamma \mathrm{H} 2 \mathrm{AX}$ and an antimouse Alexa566. Nuclei were stained with DAPI (blue). Scale bar $50 \mu \mathrm{m}$. Images were taken and analyzed using ImageJ for quantification. The percentage of $\gamma \mathrm{H} 2 \mathrm{AX}$ stained cells corresponds to the average of three independent experiments. Error bars represent standard deviations. Student's t-test was performed: ${ }^{*} \mathrm{P}<0.05,{ }^{* *}<0.01,{ }^{* * *} \mathrm{P}<0.001$.

\section{DISCUSSION}

Traditionally, recombinant proteins with multivalency and multifunction are designed by genetic engineering or chemical conjugation. ${ }^{4,8}$ For genetic engineering, combining two different proteins in one entity can lead to major issues such as misfolding, aggregation or low levels of expression. For chemical conjugation, procedures may be nonsite specific and may hamper protein activity, or may be not feasible in complex media or inside of living cells. Self-associating peptides are also often used to facilitate the conjugation of multimeric complexes composed of either the same polypeptide using domains such as $\mathrm{GCN} 4^{3}$, or 
different polypeptides using the pair Fos/Jun ${ }^{28}$, the Barnase-Barstar module ${ }^{29}$ or the Dockand-Lock system. ${ }^{30}$ While Fos/Jun peptides allow only an enrichment of the heterodimer product, both the Barnase-Barstar and the Dock-and-Lock technologies rely on disulfide bridges formation and cannot take place in living cells. In addition, the Barnase-Barstar module increases significantly the molecular mass of the multimeric complex.

We developed an alternative to overcome these limitations, and took advantage of the E3 and K3 modified tetramerization domains of p53.

The association behavior of E3 and K3 peptides evaluated by molecular modeling show that charge-reversal mutations at the interfaces of E3 and $\mathrm{K} 3$ peptides favor the stabilization of the heterotetramer assemblies, (K3E3)(E3K3) and (K3K3)(E3E3), whereas strong electrostatic repulsions disfavor the homotetramer $(E 3)_{4}$. Thus, only one homotetramer can be formed, the $(\mathrm{K} 3)_{4}$. These data were confirmed by in vitro experiments, which demonstrate that the pairing preferences led exclusively to the formation of heterotetramer complexes to the detriment of the $(\mathrm{K} 3)_{4}$ homotetramer. No homotetramer $(E 3)_{4}$ could be observed. Denaturation experiments also confirmed the gain of stability for the heterotetramers compared to the homotetramers with a melting temperature raised by $10^{\circ} \mathrm{C}$. More astonishingly, CD signals of the heat-denatured tetramers were almost completely regenerated upon cooling, suggesting an important resilience of the secondary structures.

Furthermore, the non-covalent interactions between E3 and K3 peptides are very strong and specific enough to allow and to maintain heterotetramerization of macromolecules inside of living cells. The con1-mCherry-E3 protein successfully associates with either an eGFP-K3 protein to detect PCNA at nuclear foci or with an anti-eGFP-VHH-K3 protein to bring the EYFP-tagged DNA polymerase $\eta$ close to PCNA. Moreover, eGFP-K3 fused to a NLS sequence successfully piggybacked E3 tagged macromolecules, such as a monoclonal antibody tagged with E3 from the cytoplasm to the nucleus compartment.

In terms of biological activities, the heterotetramer composed of the anti-PCNA and the con1 peptide results in higher apparent binding efficiency compared to the monovalent counterparts, inducing a markedly increased efficiency to inhibit DNA replication in living cells triggering a replicative stress and ultimately cell death.

In conclusion, we report the usefulness of E3 and K3 peptides as elements for tethering two distinct modular entities into heterotetramers that combined the functionalities of the independent modules. Connecting E3 and K3 peptides to macromolecules do not compromise the activity of the fusion partners, and can be easily achieved by genetic engineering or chemically. The non-covalent interaction between E3 and K3 peptides occurs rapidly, is very specific, remarkably stable and takes place in complex media and in living 
cells. Altogether, these E3 and K3 tags represent a versatile method for conjugating macromolecules and should open new perspectives for modular engineering of bi-specific and bi-functional biomolecules to a plethora of applications ${ }^{31}$.

\section{Experimental procedures}

\section{Cell Lines}

HeLa, MRC5 and U2OS cells were maintained as monolayer in Dulbecco's modified Eagle's medium (DMEM) supplemented with $4.5 \mathrm{~g} / \mathrm{L}$ glucose and $10 \%$ fetal calf serum (FCS) and 1 $\mathrm{mM}$ pyruvate. Cells were transiently transfected using JetpEl reagent (Polyplus transfection, Illkirch) according to the manufacturer's protocol. After $24 \mathrm{~h}$, cells were harvested in phosphate-buffered saline (PBS) and re-suspended in RIPA buffer (150 mM NaCl, $20 \mathrm{mM}$ Tris $\mathrm{HCl}, \mathrm{pH} 7.8,0.1 \%$ SDS, $1 \%$ Triton $\mathrm{X}-100,0.5 \%$ sodium deoxycholate, $1 \times$ Protease Inhibitor Cocktail (SIGMA)). After $30 \mathrm{~min}$ on ice, the resulting crude suspension was cleared by centrifugation for $5 \mathrm{~min}$ at $4000 \mathrm{xg}$ and the supernatant was identified as total cell extract. Electroporation of mAbs and recombinant proteins in living cells was performed as previously described. ${ }^{17}$ For the EdU experiments, EdU was added to the cells grown on glass coverslips for $12 \mathrm{~h}$ at a concentration of $0.5 \mu \mathrm{M}$. The incorporated EdU was visualized with the Click-iT EdU AlexaFluor 488 imaging kit (Life Technologies), according to manufacturer's protocol.

\section{Expression and purification of the recombinant fusion proteins}

Briefly, E3 and $\mathrm{K} 3$ fusion proteins and PCNA were overexpressed in E. coli BL21 (DE3) pLysS at $20^{\circ} \mathrm{C}$ in auto-induction in ZYM-5052 medium. ${ }^{32}$ Proteins were purified on HiTrapTM Chelating resin $(1 \mathrm{ml})$ saturated with cobalt (GE Healthcare Saclay, France) and subsequently loaded on Superdex 200 Increase 10/300 GL column (GE Healthcare, Biosciences $A B$, sweden) operating at a flow rate of $0.4 \mathrm{ml} / \mathrm{min}$. Fractions were separated on SDS-PAGE gradient gels and analyzed by Coomasie blue. Heterotetramers were formed by mixed together the $\mathrm{E} 3$ and $\mathrm{K} 3$ recombinant proteins with 1:1 molar ratio.

\section{Recombinant plasmid constructions}

The DNA sequences encoding E3 and K3 peptides were synthetized by Integrated DNA Technologies (IDT) and inserted into pETOM-anti-PCNA containing a c-myc sequence described elsewhere ${ }^{33}$ given the $\mathrm{PETOM}$-anti-PCNA-E3 and pETOM-anti-PCNA-K3 plasmids, respectively. The $\mathrm{pETOM}-\mathrm{con} 1-\mathrm{E} 3$ and $\mathrm{pETOM}-\mathrm{con} 1-\mathrm{K} 3$ constructs were obtained by 
replacing the anti-PCNA sequence by the annealed oligonucleotides encoding the con1 peptide (SAVLQKKITDYFHPKK) ${ }^{16}$.

To generate eukaryotic expression vectors used in this study, con1- with the c-myc sequences fused to E3 or to K3 coding sequences were first amplified by PCR from pETOMcon1-E3 vector or from pETOM-con1-K3 vector, respectively, and cloned into the pßA-based vector. ${ }^{33}$ The resulting plasmids were then used to clone the coding sequences of mCherry between the con1- coding sequences and $E 3$ or $K 3$, given rise to the pßA-con1-mCherry-E3 and pßA-con1-mCherry-K3, respectively. The pßA-eGFP-E3 and pßA-eGFP-NLS-K3 were constructed by introducing the eGFP, coding sequences into pßA derivatives E3 and K3 plasmids. Sequences of DNA constructs were verified by DNA sequencing. The EYFP-DNA polymerase $\eta$ expression plasmid has been described elsewhere ${ }^{34}$.

\section{Enzyme-linked immunosorbent assay (ELISA)}

Indirect ELISA, which usually involves two binding processes of primary antibody and secondary labeled antibody was modified as follow: Maxisorp microtiter plates (Nunc, Denmark) were coated with $20 \mu \mathrm{g} / \mathrm{ml}$ of recombinant PCNA in phosphate buffer, PBS, $\mathrm{pH}$ 8, for $16 \mathrm{~h}$ at $4{ }^{\circ} \mathrm{C}$. Wells were blocked with $0.2 \mathrm{ml}$ of $2 \%(\mathrm{w} / \mathrm{v})$ milk in PBS, $\mathrm{pH} 7.4$, containing $0.1 \%(\mathrm{v} / \mathrm{v})$ of Tween-20 for $1 \mathrm{~h}$ at RT. A dilution series of purified tagged proteins was added to the pre-coated microtiter plates beginning with a concentration of $10 \mu \mathrm{M}$ and incubated $\mathrm{ON}$ at $4{ }^{\circ} \mathrm{C}$. After extensive washing with PBS, recombinant proteins were detected with a secondary c-myc 9E10 mouse antibody followed by a ternary peroxidase conjugated antimouse antibody (Dianova, Germany) at $2 \mu \mathrm{g} / \mathrm{ml}$. The signal was developed by addition of $100 \mathrm{\mu l} /$ well of TMB color reagent (sodium acetate $0.1 \mathrm{M}, \mathrm{pH} 6.6,0.1 \mathrm{mg} / \mathrm{ml}$ of 3, 3', 5, 5'tetramethylbenzidine (TMB), $2 \mu \mathrm{l}$ of $35 \%$ Hydrogen peroxide, and stopped with $50 \mu \mathrm{l}$ of sulfuric acid at $0.45 \mathrm{M}$. The signal was monitored with a ELISA plate reader (BioRad 550) at a wavelength of $450 \mathrm{~nm}$.

\section{Immunofluorescence}

The cells grown on coverslips were fixed with $4 \%(\mathrm{w} / \mathrm{v})$ paraformaldehyde for $30 \mathrm{~min}$ and then permeabilized with $0.2 \%$ Triton $X-100$ for $5 \mathrm{~min}$. In some experiments, the cells were treated with ice-cold cytoskeletal buffer (CSK: $10 \mathrm{mM}$ HEPES pH 6.8, $100 \mathrm{mM} \mathrm{NaCl}, 300$ $\mathrm{mM}$ sucrose, $3 \mathrm{mM} \mathrm{MgCl}$, $1 \mathrm{mM}$ EGTA) with $0.2 \%$ Triton-X100 for 5 min prior fixation prior. Cells were either observed by direct immunofluorescence or further incubated with the purified recombinant proteins in PBS at $10 \mathrm{nM}$ or with the mAb anti- $\gamma \mathrm{H} 2 \mathrm{AX}$ at 1/1000 (05-636 Millipore/Upstate). The recombinant proteins were then detected with the anti-myc 9E10 monoclonal antibody (1/3000) followed by anti-mouse antibody conjugated with Alexa Fluor 488 (Life Technologies) as described previously. ${ }^{33}$ The mAb anti- $\gamma \mathrm{H} 2 \mathrm{AX}$ was detected with 
Alexa Fluor 680 (Life Technologies). The coverslips were mounted with Fluoromount G containing 4',6'-diamidino-2 phenyleindole (SouthernBiotech, Birmingham, UK). The treated cells were analyzed using conventional fluorescence microscopy with a Leica DM5500 microscope (Leica Microsystems, Wetzlar, Germany). Images were processed with Image J2.0.0.

\section{Separation and analysis of proteins by non-denaturing polyacrylamide gel electrophoresis}

Whole cell extracts from cells expressing either eGFP-E3 or mCherry-K3 proteins were prepared as previously described. ${ }^{21}$ eGFP-E3 expressing extracts were mixed with an increased amount of $\mathrm{mCherry-K3}$ expressing cell extracts. Complexes were resolved on nondenaturing polyacrylamide gradient gel (5-20\%) at $\mathrm{pH} 8.8$ and analyzed by Typhoon FLA 9500 biomolecular imager (GE Healthcare) at $470 \mathrm{~nm}$ and $555 \mathrm{~nm}$.

\section{Pull down assays}

E. coli (BRLDE3 strain) expressing His-Flag or His-Flag-p12 (WT or mutated in the PIP domain: $\mathrm{p} 12 \mathrm{~K} 4 \mathrm{~A} / \mathrm{I7A} / \mathrm{S} 10 \mathrm{~A} / \mathrm{Y} 11 \mathrm{~A}$ ) were lysed in buffer containing $40 \mathrm{mM}$ Hepes $\mathrm{pH}$ 7.9, 150 $\mathrm{mM} \mathrm{NaCl}, 1 \mathrm{mM}$ EDTA, 0,05\% Tween, 5\% glycerol. After sonication and clarification, PCNA WT or mutants (300 $\mathrm{ng}$ ) was added to the clear lysate (1 mg of total clear extract in $500 \mu \mathrm{l}$ ) and was incubated overnight with anti-FLAG M2 magnetic beads (Sigma) pre-equilibrated in lysis buffer. Beads were washed three times with the lysis buffer. Elution fractions were analyzed by $12 \%$ SDS/PAGE followed immuno-blotting using anti-Flag antibody or an antiPCNA mAb (PC10).

\section{Peptide-Antibody chemical conjugate}

The peptide E3: CALNNGEYFTLQIRGRERFEMFRELNEALELEDAQA synthetized by GeneCust (Luxemburg) was freshly dissolved in water before use and the peptide concentration of the thiol was measured using the Ellman's reagent. ${ }^{35}$ The discrepancy between the thiol concentration and the calculated one from the weighted powder was less than $20 \%$. Prior conjugation, the monoclonal antibody $(\mathrm{mAb})$ was purified as previously described. ${ }^{21}$ Reaction was carried on ice. $\mathrm{N}$-Succinimidyl 4-(maleimidomethyl) cyclohexane carboxylate (SMCC) $(1.2 \mathrm{mg} ; 3.59 \mu \mathrm{mol})$ was freshly dissolved in DMSO (360 $\mu \mathrm{l})$ to a $10 \mathrm{mM}$ final concentration. The SMCC ( $1 \mu \mathrm{L}$ of a $10 \mathrm{mM}$ solution in DMSO) was rapidly added to the $\mathrm{mAb}(100 \mu \mathrm{l}$ of a $13.33 \mu \mathrm{M}$ in PBS) on ice. The reaction was led to proceed overnight. Excess unreacted SMCC was removed by filtration using a 7K MWCO Zeba Spin column ( $0.5 \mathrm{ml}$ bed volume). The maleimido-grafted antibody was then reacted with the peptide $(2.2$ $\mu \mathrm{l}$ of a $12 \mathrm{mM}$ solution in water) for $1 \mathrm{~h}$. The disulfide bridges were reduced to thiol by addition 
of TCEP, pH 7.0 ( $2 \mu$ l of a $30 \mathrm{mM}$ solution) and excess thiols were then blocked with N-ethylmaleimide $(1 \mu \mathrm{l}$ of a $0.1 \mathrm{M}$ solution in DMSO) for $1 \mathrm{~h}$. The crude mixture was then purified using an ultracentifugation $50 \mathrm{KDa}$ Ambion Device $(0.5 \mathrm{ml}, 5 \times 0.5 \mathrm{ml})$.

\section{Collect of p53 tet PDB records and protein structure statistics}

p53 tetramer structures were collected from the Protein Data Bank (PDB) ${ }^{36}$ using a BLASTP sequence similarity search (default parameters) on the $\mathrm{NCBI}$ web server (http://www.ncbi.nlm.nih.gov) with the human p53 tetramer sequence (RefSeq:NP_000537) from residue G325 to G356 as a query. Human and x-ray crystallographic structures were selected. A total of 7 structures were retrieved from the PDB, i.e. 1AIE, 1C26, 3Q01, 3Q05, 3Q06, 3TS8, 4MZR and were processed with the protein structure statistics (PSS) tool. ${ }^{37} \mathrm{C} \alpha$ backbone structural variations were weak $(<1 \AA)$ indicating that the structures of the small domain are well defined and do not display large flexible regions (data not shown).

\section{D molecular models}

PDB ID $1 \mathrm{C}^{2} 6^{9}$ was used as a starting structure to construct 3D models of dimers and tetramers. Water molecules were discarded. In PyMOL, residues Glu 343, Glu 346 and Lys 351 were mutated to generate the E3 and K3 monomers. Side-chain structural orientations were refined with GalaxyWeb. ${ }^{38}$ The protonation state of titratable residues was determined at $\mathrm{pH} 7.4$ with the PROPKA program ${ }^{39}$ implemented in the PDB2PQR server. ${ }^{40}$ Hydrogen atom placement on the proteins was performed using the HBUILD ${ }^{41}$ facility in the CHARMM program. ${ }^{42}$ The energies of complexes were minimized with 500 steps of steepest descent (SD) algorithm using CHARMM program version c37b1 with non-bonded interactions truncated at a $14 \AA$ cutoff distance using switch and shift functions for van der Waals and electrostatic forces, respectively.

\section{Binding free energies}

An automated procedure based on the Molecular mechanics Poisson-Boltzmann surface area (MM/PBSA) method ${ }^{12}$ was used to obtain the total and per-residue energetic contribution to homodimer formation. The binding free energy variation between 2 proteins upon association can be expressed by the Gibbs free energy definition

$$
\begin{aligned}
& \Delta \mathrm{G}_{\text {asso }}=\Delta \mathrm{H}-\mathrm{T} \Delta \mathrm{S} \\
& \Delta \mathrm{G}_{\text {asso }} \approx \Delta \mathrm{E}_{\mathrm{MM}}+\Delta \mathrm{G}_{\text {solv }}-\mathrm{T} \Delta \mathrm{S}
\end{aligned}
$$

where $\Delta \mathrm{E}_{\mathrm{MM}}$ is the total molecular mechanical energy variation, $\Delta \mathrm{G}_{\text {solv }}$ is the solvation free energy variation and $-\mathrm{T} \Delta \mathrm{S}$ is the conformational entropy variation upon complex formation. $\Delta \mathrm{E}_{\mathrm{MM}}$ can be calculated as 


$$
\Delta \mathrm{E}_{\mathrm{MM}}=\Delta \mathrm{E}_{\text {internal }}+\Delta \mathrm{E}_{\text {elec }}+\Delta \mathrm{E}_{\mathrm{vdw}}
$$

where $\Delta \mathrm{E}_{\text {internal }}$ is the energy variation associated with bond lengths, angles and dihedrals, $\Delta \mathrm{E}_{\text {elec }}$ and $\Delta \mathrm{E}_{\mathrm{vdw}}$ represent electrostatic and vdW terms, respectively.

$$
\Delta \mathrm{G}_{\text {solv }}=\Delta \mathrm{G}_{\mathrm{PB}}+\Delta \mathrm{G}_{\mathrm{SA}}
$$

$\Delta G_{P B}$ and $\Delta G_{S A}$ are solvation energy variation associated with polar and non-polar contributions, respectively. For the sake of comparing different tetramer architectures, we were mostly interested in the contributions that differ most between the WT and mutants tetramers/dimers. The contribution of the conformation entropy to complex formation, as well as the change in internal energy upon binding, $\Delta \mathrm{E}_{\text {internal, }}$ was therefore neglected (see Equation 5).

$$
\Delta \mathrm{G}_{\mathrm{asso}}=\Delta \mathrm{E}_{\mathrm{elec}}+\Delta \mathrm{E}_{\mathrm{vdw}}+\Delta \mathrm{G}_{\mathrm{PB}}+\Delta \mathrm{G}_{\mathrm{SA}}
$$

The protein and solvent contribution to the electrostatics term were calculated using the University of Houston Brownian Dynamics (UHBD) ${ }^{13}$ with a grid spacing of $0.3 \AA$ and a protein dielectric constant of 1 . The $\mathrm{vdW}$ and solvent accessible terms were calculated using CHARMM. This procedure has been shown to provide ranking of affinities that are coherent with experimental data in several studies. As a result of the approximations inherent to the method, absolute values of the free energy computed by Eq. (5) should however not be directly compared to experimental binding affinities. For details see. ${ }^{12}$ The MM/PBSA calculations were performed on the minimized structures of the complexes.

\section{Circular dichroism}

CD experiments were recorded on a Jasco J-815 spectropolarimeter (Easton, MD, USA) equipped with an automatic 6-position Peltier thermostated cell holder. The instrument was calibrated with 10-camphorsulphonic acid. Far-UV CD data were collected in the 185-270 nm range using a $0.1 \mathrm{~mm}$ pathlength cell (Quartz-Suprasil, Hellma UK Ltd) at $20.0^{\circ} \mathrm{C} \pm 0.1{ }^{\circ} \mathrm{C}$. Acquisition parameters as continuous scan rate, response time and bandwidth were 50 $\mathrm{nm} / \mathrm{min}, 1.0 \mathrm{sec}$ and $1 \mathrm{~nm}$, respectively. Spectra are presented as an average of 5 successive scans. The absorbance of the buffer and the sample was kept as low as possible to ensure good signal-to-noise ratio: con1 tagged E3 and K3 spectra were carried out in phosphate-buffered saline (PBS: $10 \mathrm{mM}$ sodium phosphate buffer, $137 \mathrm{mM} \mathrm{NaCl}, \mathrm{pH} 7.4$ ) at a monomeric concentration of $50 \mu \mathrm{M}$. All spectra are systematically corrected by subtracting the solvent spectrum obtained under identical conditions. The signal is expressed in mean residue ellipticity $\left(\right.$ deg. $\left.\mathrm{cm}^{2} \cdot \mathrm{dmol}^{-1}\right)$. The secondary structure was estimated with the CDPro suite software (Sreerama and Woody, 2000). The spectra of E3 and K3 constructs have been deposited in the Protein Circular Dichroism Data Bank ${ }^{43}$ (http://pcddb.cryst.bbk.ac. uk) 
with the accession codes CD0006186000 and CD0006187000 for release upon publication. For thermal denaturation and renaturation experiments, unfolding of the secondary structures of the samples at $100 \mu \mathrm{M}$ in PBS was followed by monitoring the changes in CD signal at $222 \mathrm{~nm}$ using a $1 \mathrm{~mm}$ path-length cell (Quartz-Suprasil, Hellma UK Ltd) for temperature ranged from 20 to $96^{\circ} \mathrm{C}$ or from $96^{\circ} \mathrm{C}$ to $20^{\circ} \mathrm{C}$ every $2^{\circ} \mathrm{C}$ with $8 \mathrm{~s}$ averaging time. The heating rate was $60 \mathrm{~K} / \mathrm{hr}$. CD signals of buffer at $222 \mathrm{~nm}$ and protein sample at $260 \mathrm{~nm}$ as a function of temperature were examined separately and did not show significant change. The fraction of the folded form (and therefore the denatured content) was extracted from the variation of $\mathrm{CD}$ signal, $\mathrm{S}$, over the temperature, using the following equation:

$f_{N}=\left[S-\left(Y_{D}+a_{D} T\right)\right] /\left[\left(Y_{N}+a_{N} T\right)-\left(Y_{D}+a_{D} T\right)\right]$

where $a_{N}, a_{D}$ and $Y_{N}, Y_{D}$ denote the slopes and the $y$-intercepts of the pre- and posttransition. Melting temperatures were determined by fitting the experimental folded fractions unsing the manufacturer's software (Jasco, Easton, MD).

\section{Acknowledgements}

This work was supported by funds and/or fellowships from the Centre National de la Recherche Scientifique, the University of Strasbourg, the French Ministry of Research, the Ligue Régionale contre le Cancer (CCIR-GE), the Fondation ARC nPJA 20151203337 and the INCA-10493. We thank G. Travé, K. Zanier and J.C. Amé for very helpful advises, and E Weiss for the scFv P40M1 clone.

\section{Supporting Information Available}

Figures showing additional modelling data, direct detection of fluorescent E3 and K3 fusion proteins, co-immuno-precipitation of PCNA mutants with p12, additional apparent binding efficiencies, detection of transduced recombinant proteins and cell survival experiments. Table showing averaged secondary structure contents of E3 and K3 domains. This material is available free of charge via the Internet at http://pubs.acs.org.

\section{References}

(1) Mammen, M., Choi, S.-K., and Whitesides, G. M. (1998) Polyvalent Interactions in Biological Systems: Implications for Design and Use of Multivalent Ligands and Inhibitors. Angew Chem Int Ed Engl 37, 2754-2794. 
(2) Pack, P., and Plückthun, A. (1992) Miniantibodies: use of amphipathic helices to produce functional, flexibly linked dimeric FV fragments with high avidity in Escherichia coli. Biochemistry 31, 1579-1584.

(3) Pack, P., Müller, K., Zahn, R., and Plückthun, A. (1995) Tetravalent miniantibodies with high avidity assembling in Escherichia coli. $J$ Mol Biol 246, 28-34.

(4) Ramirez, J., Poirson, J., Foltz, C., Chebaro, Y., Schrapp, M., Meyer, A., Bonetta, A., Forster, A., Jacob, Y., Masson, M., et al. (2015) Targeting the Two Oncogenic Functional Sites of the HPV E6 Oncoprotein with a High-Affinity Bivalent Ligand. Angew. Chem. Int. Ed. 127, 7958-7962.

(5) Alvarez-Cienfuegos, A., Nuñez-Prado, N., Compte, M., Cuesta, A. M., Blanco-Toribio, A., Harwood, S. L., Villate, M., Merino, N., Bonet, J., Navarro, R., et al. (2016) Intramolecular trimerization, a novel strategy for making multispecific antibodies with controlled orientation of the antigen binding domains. Sci. Rep. 1-14.

(6) Pechar, M., Pola, R., Laga, R., Ulbrich, K., Bednárová, L., Maloň, P., Sieglová, I., Král, V., Fábry, M., and Vaněk, O. (2011) Coiled coil peptides as universal linkers for the attachment of recombinant proteins to polymer therapeutics. Biomacromolecules 12, 3645-3655.

(7) Xu, L., Pegu, A., Rao, E., Doria-Rose, N., Beninga, J., McKee, K., Lord, D. M., Wei, R. R., Deng, G., Louder, et al. (2017) Trispecific broadly neutralizing HIV antibodies mediate potent SHIV protection in macaques. Science 358, 85-90.

(8) Kishimoto, S., Nakashimada, Y., Yokota, R., Hatanaka, T., Adachi, M., and Ito, Y. (2019) Site-Specific Chemical Conjugation of Antibodies by Using Affinity Peptide for the Development of Therapeutic Antibody Format. Bioconjugate Chem. acs.bioconjchem.8b00865.

(9) Jeffrey, P. D., Gorina, S., and Pavletich, N. P. (1995) Crystal structure of the tetramerization domain of the p53 tumor suppressor at 1.7 angstroms. Science 267, 14981502.

(10) Clore, G. M., Omichinski, J. G., Sakaguchi, K., Zambrano, N., Sakamoto, H., Appella, E., and Gronenborn, A. M. (1994) High-resolution structure of the oligomerization domain of p53 by multidimensional NMR. Science 265, 386-391.

(11) Brokx, R. D., Bolewska-Pedyczak, E., and Gariépy, J. (2003) A stable human p53 heterotetramer based on constructive charge interactions within the tetramerization domain. J Biol Chem 278, 2327-2332.

(12) Lafont, V., Schaefer, M., Stote, R. H., Altschuh, D., and Dejaegere, A. (2007) Proteinprotein recognition and interaction hot spots in an antigen-antibody complex: Free energy decomposition identifies "efficient amino acids." Proteins 67, 418-434.

(13) Madura, J. D., Briggs, J. M., Wade, R. C., E, D. M., Luty, B. A., Ilin, A., Antosiewicz, J., Gilson, M. K., Bagheri, B., Scott, L. R., and McCammon, J. A. (1995) Electrostatics and diffusion of molecules in solution: simulationswith the University of Houston Brownian Dynamics program 1-39.

(14) Moldovan, G.-L., Pfander, B., and Jentsch, S. (2007) PCNA, the Maestro of the Replication Fork. Cell 129, 665-679.

(15) Wang, S.-C. (2014) PCNA: a silent housekeeper or apotential therapeutic target? Trends in Pharmacological Sciences 35, 178-186.

(16) Zheleva, D. I., Zhelev, N. Z., Fischer, P. M., Duff, S. V., Warbrick, E., Blake, D. G., and Lane, D. P. (2000) A quantitative study of the in vitro binding of the C-terminal domain of p21 to PCNA: affinity, stoichiometry, and thermodynamics. Biochemistry 39, 7388-7397.

(17) Freund, G., Sibler, A.-P., Desplancq, D., Oulad-Abdelghani, M., Vigneron, M., Gannon, J., Van Regenmortel, M. H., and Weiss, E. (2013) Targeting endogenous nuclear antigens by electrotransfer of monoclonal antibodies in living cells. mabs 5, 518-522.

(18) Sreerama, N., and Woody, R. W. (2000) Estimation of Protein Secondary Structure from Circular Dichroism Spectra: Comparison of CONTIN, SELCON, and CDSSTR Methods with an Expanded Reference Set. Anal Biochem 287, 252-260.

(19) Vaisman, A., and Woodgate, R. (2017) Translesion DNA polymerases in eukaryotes: what makes them tick? Critical Reviews in Biochemistry and Molecular Biology 52, 274-303.

(20) Rothbauer, U., Zolghadr, K., Tillib, S., Nowak, D., Schermelleh, L., Gahl, A., Backmann, 
N., Conrath, K., Muyldermans, S., Cardoso, M. C., and Leonhardt, H. (2006) Targeting and tracing antigens in live cells with fluorescent nanobodies. Nat Methods 3, 887-889.

(21) Schaeffer, E., Vigneron, M., Sibler, A.-P., Oulad-Abdelghani, M., Chatton, B., and Donzeau, M. (2015) ATF7 is stabilized during mitosis in a CDK1-dependent manner and contributes to cyclin D1 expression. Cell Cycle 14, 2655-2666.

(22) Diring, J., Camuzeaux, B., Donzeau, M., Vigneron, M., Rosa-Calatrava, M., Kedinger, C., and Chatton, B. (2011) A cytoplasmic negative regulator isoform of ATF7 impairs ATF7 and ATF2 phosphorylation and transcriptional activity. PLOS ONE 6, e23351.

(23) Yoshida, K., Maekawa, T., Zhu, Y., Renard-Guillet, C., Chatton, B., Inoue, K., Uchiyama, T., Ishibashi, K.-I., Yamada, T., Ohno, N., et al. (2015) The transcription factor ATF7 mediates lipopolysaccharide-induced epigenetic changes in macrophages involved in innate immunological memory. Nature Immunology 16, 1034-1043.

(24) Gonzalez-Magaña, A., Ibáñez de Opakua, A., Romano-Moreno, M., Murciano-Calles, J., Merino, N., Luque, I., Rojas, A. L., Onesti, S., Blanco, F. J., and De Biasio, A. (2019) The p12 subunit of human polymerase $\delta$ uses an atypical PIP box for molecular recognition of proliferating cell nuclear antigen (PCNA). J Biol Chem 294, 3947-3956.

(25) Chen, J., Richard Peters, Saha, P., Lee, P., Theodoras, A., Pagano, M., Wagner, G., and Dutta, A. A 39 amino acid fragment of the cell cycle regulatorp21 is sufficient to bind PCNA and partially inhibitDNA replication in vivo.

(26) Zeman, M. K., and Cimprich, K. A. (2014) Causes and consequences of replication stress. Nat Cell Biol 16, 2-9.

(27) Kuo, L. J., and Yang, L.-X. (2008) Gamma-H2AX - a novel biomarker for DNA doublestrand breaks. In Vivo 22, 305-309.

(28) Kostelny, S. A., Cole, M. S., and Tso, J. Y. (1992) Formation of a bispecific antibody by the use of leucine zippers. J. Immunol. 148, 1547-1553.

(29) Deyev, S. M., Waibel, R., Lebedenko, E. N., Schubiger, A. P., and Plückthun, A. (2003) Design of multivalent complexes using the barnase-barstar module. Nat Biotechnol 21, 1486-1492.

(30) Rossi, E. A., Goldenberg, D. M., and Chang, C.-H. (2012) The dock-and-lock method combines recombinant engineering with site-specific covalent conjugation to generate multifunctional structures. Bioconjugate Chem. 23, 309-323.

(31) De Meyer, T., Muyldermans, S., and Depicker, A. (2014) Nanobody-based products as research and diagnostic tools $1-8$.

(32) Studier, F. W. (2005) Protein production by auto-induction in high density shaking cultures. Protein Expr Purif 41, 207-234.

(33) Freund, G., Desplancq, D., Stoessel, A., Weinsanto, R., Sibler, A.-P., Robin, G., Martineau, P., Didier, P., Wagner, J., and Weiss, E. (2014) Generation of an intrabody-based reagent suitable for imaging endogenous proliferating cell nuclear antigen in living cancer cells. J. Mol. Recognit. 27, 549-558.

(34) Baldeck, N., Janel-Bintz, R., Wagner, J., Tissier, A., Fuchs, R. P., Burkovics, P., Haracska, L., Despras, E., Bichara, M., Chatton, B., and Cordonnier, A. M. (2015) FF483484 motif of human Pol mediates its interaction with the POLD2 subunit of Pol and contributes to DNA damage tolerance. Nucleic Acids Research 43, 2116-2125.

(35) ELLMAN, G. L. (1959) Tissue sulfhydryl groups. Archives of Biochemistry and Biophysics 82, 70-77.

(36) Berman, H. M., Westbrook, J., Feng, Z., Gilliland, G., Bhat, T. N., Weissig, H., Shindyalov, I. N., and Bourne, P. E. (2000) The Protein Data Bank. Nucleic Acids Research 28, 235-242.

(37) Gaillard, T., Schwarz, B. B. L., Chebaro, Y., Stote, R. H., and Dejaegere, A. (2013) Protein Structural Statistics with PSS. J. Chem. Inf. Model. 53, 2471-2482.

(38) Heo, L., Lee, H., and Seok, C. (2016) GalaxyRefineComplex: Refinement of proteinprotein complex model structures driven by interface repacking. Sci. Rep. 1-10.

(39) Rostkowski, M., Olsson, M. H. M., Søndergaard, C. R., and Jensen, J. H. (2011) Graphical analysis of $\mathrm{pH}$-dependent properties of proteins predicted using PROPKA. BMC Struct. Biol. 11, 1-6. 
(40) Dolinsky, T. J., Nielsen, J. E., McCammon, J. A., and Baker, N. A. (2004) PDB2PQR: an automated pipeline for the setup of Poisson-Boltzmann electrostatics calculations. Nucleic Acids Research 32, W665-W667.

(41) Brünger, A. T., and Karplus, M. (1988) Polar hydrogen positions in proteins: empirical energy placement and neutron diffraction comparison. Proteins 4, 148-156.

(42) Brooks, B. R., Brooks, C. L., III, Mackerell, A. D., Jr., Nilsson, L., Petrella, R. J., Roux, B., Won, Y., Archontis, G., Bartels, C., Boresch, S., et al. (2009) CHARMM: The biomolecular simulation program. J. Comput. Chem. (Brooks, C. L., III, and Case, D. A., Eds.) 30, 15451614.

(43) Whitmore, L., Woollett, B., Miles, A. J., Klose, D. P., Janes, R. W., and Wallace, B. A. (2010) PCDDB: the protein circular dichroism data bank, a repository for circular dichroism spectral and metadata. Nucleic Acids Research 39, D480-D486. 
TOC Graph

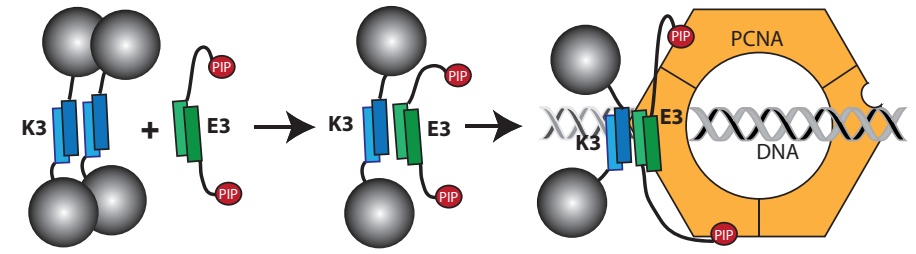

